INTERNATIONAL RESEARCH COUNCIL

\title{
INTERNATIONAL ASTRONOMICAL UNION
}

\author{
(UNION ASTRONOMIQUE INTERNATIONALE) \\ 1928-1932
}

EXECUTIVE COMMITTEE

PRESIDENT:

Sir F. W. Dyson, Astronomer Royal, Royal Observatory, Greenwich, England.

VICE-PRESIDENTS:

Prof. G. Aвetti, Direttore del R. Osservatorio Astrofisico, Arcetri-Firenze, Italia.

Prof. H. Andoyer, Professeur d'Astronomie à la Faculté des Sciences à la Sorbonne, Paris, France.

Prof. N. E. NöRLUND, Director of the Danish Geodetic Institute and Professor of Mathematics in the University of Copenhagen, Denmark.

Prof. F. NušL, Professeur d'Astronomie dans la Karlova Université et Directeur de l'Observatoire National, Prague, Tchécoslovaquie.

Prof. F. Schlesinger, Professor of Astronomy in Yale University and Director of the Yale University Observatory, New Haven, Connecticut, U.S.A.

GENERAL SECRETARY:

Prof. F. J. M. Stratron, Director of the Solar Physics Observatory, Cambridge; Gonville and Caius College, Cambridge, England. 